\title{
PRODUÇÃO E CIRCULAÇÃO DOS LIVROS ESCOLARES DE THOMAZ GALHARDO: A SÉRIE GRADUADA NA ESCOLA E NO $L A R$
}

\author{
Production and circulation of school books by Thomaz Galhardo: the graduated \\ series na escola e no lar
}

Producción y circulación de los libros escolares de Thomaz Galhardo: la serie graduada na escola e no lar

Lucilene Rezende Alcanfor ${ }^{1}$

\begin{abstract}
Resumo
Este artigo é resultado de um estudo historiográfico da produção e circulação dos livros escolares de Thomaz Galhardo (1852-1904). Professor de instrução primária, que fez da sua trajetória uma ação política no cenário público educacional paulista no final do Império e nas primeiras décadas da República, Thomaz Galhardo fez parte de uma nova geração de autores de livros didáticos, originários do ensino primário, que passaram a produzir séries graduadas de livros de leitura. Destacou-se no mercado editorial pela produção desse tipo de literatura escolar, principalmente, como autor da tão conhecida Cartilha da Infância, editada de 1888 a 1991, pertencente à série $N a$ escola e no lar. Além da Cartilha, a série graduada é composta pela Segundo Livro de Leitura para a Infância e Terceiro Livro de Leitura para a Infância. Estas obras são objeto de análise deste artigo, situando-as no contexto de produção e circulação de livros escolares entre os séculos XIX e XX. Com base no arcabouço teórico e metodológico de Alain Choppin, procuramos inventariar o processo editorial das obras de Thomaz Galhardo, atentando para as peculiaridades do mercado de livros didáticos do período.
\end{abstract}

PALAVRAS-CHAVE: Thomaz Galhardo. Cartilha. Série Graduada.

\begin{abstract}
This article is the result of a historiographical study of the production and circulation of Thomaz Galhardo (1852-1904) school books. A primary education teacher, who made from his production a political action in the public education scene of São Paulo state during the end of the Empire and the first decades of Republic, Thomaz Galhardo was part of a new generation of didactic books authors that, from primary education, started to produce a graduated series of reading books. He stood out in the publishing market for this type of didactic material, especially as the author of the so well-known Spelling Book for Children (Cartilha da Infância), a book edited from 1888 to 1991, which is part of the series At School and at Home (Na escola e no Lar). Besides the Spelling Book, the graduated series incorporates the Second Reading Book for Children (Segundo Livro de Leitura para a Infância) and Third Reading Book for Children (Terceiro Livro de Leitura para a Infância). These works are analyzed in this article, placed in the context of production and circulation of school books within XIX and XX centuries. Based on theoretical and methodological framework of Alain Choppin, this study intends to create an inventory of the editorial process of Thomaz
\end{abstract}

\footnotetext{
${ }^{1}$ Professora adjunta do curso de Pedagogia da Universidade da Integração Internacional da Lusofonia AfroBrasileira (UNILAB - CE). Mestre e doutora em História da Educação pelo programa de estudos pósgraduados em Educação: História, Política, Sociedade, da Pontifícia Universidade Católica de São Paulo (PUC-SP). Email: lucilenealcanfor@unilab.edu.br.
} 
Galhardo works, with particular attention to the peculiarities of the market for school books on that period.

KEYWORDS: Thomaz Galhardo. Spelling Book. Graduated Series.

\section{Resumen}

Este articulo es resultado de um estudio historiográfico de la produccion y circulacion de los libros escolares de Thomaz Galhardo (1852 - 1904). Profesor de instrucción primaria, que hizo de su trayectoria una accion política en el escenario público educacional paulista en el final de império y en las primeras décadas de la república, Thomaz Galhardo hizo parte de uma generación de autores de libros didácticos, originarios de enseñanza primaria, que assaram a produzir series graduadas de libros de lectura. Destaco en el mercado editorial por la produccion de esse tipo de literatura escolar, principalmente como autor de tan conocida Cartilha da Infância, editada entre 1888 a 1991 e perteneciente a la serie Na escola e no lar. Ademas de la Cartilha, la serie graduada es compuesta por el Segundo livro de leitura para a infância, e Terceiro livro de leitura para a infância. Estas obras son objeto de analisis de este articulo, situándolas en el contexto de producción y circulación de libros escolares, entre los siglos XIX e XX. Com base en el estructura teórica y metodológico de Alan Choppin, buscamos inventariar el processo editorial de las obras de Thomaz Galhardo, atentando para las peculiaridades del mercado de libros didácticos del período.

PALABRAS CLAVE: Thomaz Galhardo. Cartilla. Serie Graduada.

\section{INTRODUÇÃO}

Thomaz Galhardo (1852-1904) é conhecido pela historiografia da educação brasileira, sobretudo por aqueles dedicados a estudar livros alfabetização e de leitura, como autor da famosa Cartilha da Infância, obra que chama a atenção pela longa duração no mercado de livros escolares e por sucessivas edições difundidas nos espaços educacionais brasileiros.

Neste trabalho apresentamos os resultados da análise das obras de Thomaz Galhardo, destacando a produção e circulação dos livros escolares deste professor, a partir dos resultados apresentados no curso de pós-graduação em nível de doutorado no programa "Educação: História, Política, Sociedade", da Pontifícia Universidade Católica de São Paulo. O estudo se insere na linha de pesquisa "História da Educação Escolar", tendo como objetos de investigação os materiais didáticos produzidos por Thomaz Galhardo, com ênfase nos livros que formam a série graduada de leitura Na escola e no lar. Essa série é composta pela Cartilha da Infância, Segundo livro de leitura para a infância e Terceiro livro de leitura para a infância, publicada entre a última década do século XIX e início do século XX.

As séries graduadas de livros de leitura originaram-se no bojo das escolas seriadas, sendo criadas para atender ao novo modelo didático-pedagógico da escola primária brasileira. Compostas de três, quatro e até cinco livros de leitura de uma mesma autoria, esses livros garantiam a continuidade dos conteúdos por lições e temas, com base em uma

\footnotetext{
${ }^{2}$ Os estudos sobre a "História da Educação Escolar" são desenvolvidos no grupo de pesquisa "História das disciplinas escolares e dos materiais didáticos”, coordenados pela Prof ${ }^{a} D^{a}$ Circe Maria Fernandes Bittencourt e pelo Prof $^{\circ}$ Dr $^{\circ}$ Kazumi Munakata.
} 
nova concepção de vida social, que precisava ser aprendida na escola, do primeiro ao último ano escolar.

No período compreendido, os saberes como leitura e escrita ganharam novas dimensões, assumiram formas mais complexas e precisavam responder às novas demandas sociais. A preocupação dos dirigentes educacionais, em traçar orientações ao que se entendia como o conjunto dos saberes elementares escolarizados, emanava a urgência da produção de materiais pedagógicos para atender às novas práticas educativas. Estes livros se tornaram a mola propulsora do mercado de manuais de ensino que, por sua vez, destacaram-se entre aqueles destinados ao trabalho de iniciação cultural, colocando em cena o mundo da escrita aos leitores iniciantes (CHARTIER, HÉBRARD, 1995).

É preciso lembrar, conforme afirma Munakata (2012) que, no processo de expansão da escolarização, ampliou-se o público leitor de livros e a existência destes possibilitou a própria escolarização da sociedade. O livro didático faz parte da vida escolar desde que a escola é escola. Nesse lugar instituído, o livro necessariamente se faz presente, não como um acessório, mas como um dispositivo fundamental. "O livro e a escola mantêm uma relação simbiótica" (MUNAKATA, 2012, p. 59).

Com base no arcabouço teórico e metodológico de Alain Choppin, procuramos inventariar a produção intelectual de Thomaz Galhardo, atentando para as peculiaridades desse objeto aparentemente banal e de múltiplas facetas, difícil de caracterizar, denominado genericamente de livro didático.

Este pesquisador da história do livro didático destacou, já no início de suas pesquisas, a importância de situar a produção didática em uma dimensão mais ampla, para além dos estudos limitados ao conteúdo das obras. Esse tipo de análise pressupõe compreender primeiramente que o livro escolar é um objeto, cuja fabricação evolui de acordo com o progresso das técnicas de produção do livro, das mudanças do mundo da edição, dos contextos políticos, econômicos e legislativos. Mas é importante destacar que o livro didático deve ser entendido como suporte privilegiado do conteúdo educativo, além de um importante instrumento pedagógico.

As investigações, sob uma perspectiva histórica, possibilitam a compreensão da complexidade e das especificidades do livro didático, tendo como princípio norteador $\mathrm{o}$ cuidado em estabelecer sua distinção quanto aos demais impressos.

Essa distinção, que se inscreve na natureza singular desse objeto, pode ser entendida, como indica Choppin (2009), sob quatro perspectivas diferentes, mas complementares: primeiramente, pela multiplicidade de denominações que são utilizadas para identificá-lo (livros de leitura, compêndios, manuais didáticos, cartilhas, antologias, epítomes, florilégios, seletas, livro do aluno, manual do professor etc.), por meio das quais se estabelecem suas funções ou usos; a segunda perspectiva tem a ver com o campo semântico, os limites e as fronteiras que separaram o "território" dos manuais escolares e das categorias editorias vizinhas, por exemplo, a literatura infantil; a terceira é sobre os suportes do manual e suas modalidades de difusão e formas de utilização; o quarto e último aspecto diz respeito às questões ligadas à categorização e à tipologia desse objeto em constante mutação.

Compreender o manual escolar em uma perspectiva do leitor também é fundamental para apreender as mudanças produzidas nos séculos XIX e XX, assim como os fatores que provocaram uma renovação das técnicas de impressão, reconhecendo o livro escolar como instrumento de base para a difusão e a democratização do ensino. Além 
disso, sua origem tem a ver especialmente com a formação dos Estados nações, o advento do capitalismo, da edição e a difusão dos novos métodos de ensino (CHOPPIN, 2009).

Como construção intelectual, a literatura escolar de Thomaz Galhardo deve ser interpretada no contexto da produção de outros autores que se destacaram como produtores de livros de leitura. É relevante conhecer a personalidade dos autores de manuais, seus centros de interesses, mas também suas atividades profissionais, suas tendências políticas, religiosas, esmiuçando as relações complexas que emergem do processo de produção dos livros escolares (CHOPPIN, 1980).

Pesquisadores do campo têm, não somente inventariado a produção desses sujeitos, mas também traçado o perfil desses intelectuais, os lugares de onde falam e seus grupos de pertencimento, enquanto produtores/autores de obras de ampla circulação e de longa duração ${ }^{3}$.

Essa nova geração de autores de inaugurou uma profícua literatura escolar, cuja popularidade explica-se tendo em vista o aparecimento de um mercado editorial específico para o gênero didático e sua adequação à estrutura do ensino primário, no qual se insere a produção de Thomaz Galhardo.

Para além da perspectiva de análise dos conteúdos de ensino, o estudo da produção e circulação dos livros escolares de Thomaz Galhardo se propõe, num primeiro momento, a agrupar as informações esparsas sobre as tiragens das publicações, perscrutando os processos de produção, bem como os lugares de sua difusão e da duração de sua utilização.

As referidas perspectivas de análise suscitam as seguintes questões: Em que contexto educacional Thomaz Galhardo produziu sua série graduada? Como e quando se deu tal processo de produção? De que maneira Thomaz Galhardo se insere na nova geração de autores de livros escolares?

Tais questões nos remetem ao estudo da produção das obras como objeto "fabricado", permeando dois aspectos: os referentes à sua "fabricação" (dificuldades pedagógicas, relações do autor com sujeitos envolvidos em sua produção, aspectos técnicos, características materiais, organização, formato dos livros e capas), e de sua "comercialização" (criação, produção, circuitos de difusão, preço, análise do mercado, investimentos, formas de publicidade) (CHOPPIN, 1980).

Neste artigo, os aspectos econômicos dos livros escolares de Thomaz Galhardo são abordados enquanto instrumento de poder, derivados das relações com o crescimento do mercado editorial e as transformações técnicas de sua fabricação. As questões financeiras, tanto referentes aos preços de venda, quanto às relações contratuais estabelecidas entre o autor e seu principal editor, Francisco Alves, bem como as relações econômicas do editor com outros autores do gênero, revelam as nuances de uma rede de influências e interesses formadores da história das edições escolares brasileiras.

\section{O despontar da literatura escolar brasileira para a instrução pública elementar}

\footnotetext{
${ }^{3}$ Alguns exemplos dessa amplitude podem ser encontrados nos estudos de Cabrini (1994), sobre a trajetória de Felisberto de Carvalho; Valdez (2006), que discutiu a infância na obra de Abílio Cesar Borges; Panizzolo (2006), ao reconstituir a trajetória profissional de João Köpke; Oriani (2010), ao realçar a atuação de Oliveira Vianna como professor e produtor de livros escolares.
} 
A ampliação da oferta do ensino público brasileiro nas últimas décadas do século XIX foi, sem dúvida, a mola propulsora do mercado de livros escolares, especificamente aqueles destinados à alfabetização e leitura. Entre 1890 e 1914, a matrícula no ensino primário paulista passa a ser dez vezes maior e, em 1904, 40\% das classes existentes destinavam-se ao primeiro ano (MONARCHA, 1999).

Constituindo-se no único livro didático permitido nas escolas públicas paulistas a partir do final do século XIX, o livro de leitura tornou-se o principal instrumento da uniformização do ensino e o mais importante auxiliar para o ensino da língua materna.

Conforme o parecer da comissão revisora dos livros didáticos para o ensino primário, que constava na publicação oficial do Anuário do Ensino do Estado de São Paulo (1907-1908), ficou determinado que os livros didáticos dividir-se-iam entre livros de leitura, facultados para uso dos alunos, compêndios e manuais, podendo servir de guia aos professores no ensino das diversas disciplinas do programa ${ }^{4}$.

A grosso modo, faziam parte dos livros de leitura as "cartilhas" e as séries graduadas de leitura, para uso do primeiro ao quarto ano escolar, não havendo clareza no texto do documento quanto às questões metodológicas e os conteúdos específicos que cada modalidade deveria tratar. Bastava que os alunos utilizassem somente os livros de leitura. Para as demais disciplinas bastariam as explicações dos mestres.

Nesse contexto, o aprendizado da leitura deveria permitir o acesso a bons livros, capazes de promover a educação moral e a doutrinação política das camadas populares. No cerne do debate, a pauta estava mais voltada para o que deveria ser lido do que para as práticas escolares da leitura, perguntando-se: que "conhecimentos, que valores, que cultura” a escola deveria transmitir? (CHARTIER, HÉBRARD, 1995, p. 257).

Cabe ainda ressaltar que os livros escolares não são simples objetos criados para implementar a prática educativa. Para além de uma interpretação reducionista, eles são "espaços de memória" das instituições de ensino e a principal ferramenta do trabalho docente. Além disso, criam um novo tipo de leitor, diferenciado, consumidor de um novo suporte textual que se define pelo contexto e pelas práticas de uso impostas pela cultura escolar (ESCOLANO, 2000, p. 171). Eles revelam, sobretudo, circuitos de poder, que refletem uma economia política controlada pelas editoras e pelos demais profissionais envolvidos em sua produção, fomentando assim novas práticas culturais.

Bittencourt (2004) sinalizou, em um dos seus estudos sobre os autores e editores de compêndios e livros de leitura, que:

O autor de uma obra didática deve ser, em princípio, um seguidor dos programas
oficiais propostos pela política educacional. Mas, além a vinculação aos ditames
oficiais, o autor é dependente do editor, do fabricante do seu texto, dependência
que ocorre em vários momentos, iniciando pela aceitação da obra para
publicação e em todo o processo de transformação do seu manuscrito em objeto
de leitura, um material didático a ser posto no mercado (BITTENCOURT, 2004,
p. 479).

Thomaz Galhardo fez parte de um grupo de professores intelectuais que Bittencourt (2004) denominou como uma segunda geração de autores de livros didáticos, voltada para a produção de livros escolares para a escola elementar. Essa geração diferenciava-se da

\footnotetext{
${ }^{4}$ Parecer apresentado ao secretário do interior pela comissão revisora dos livros didáticos, composta por Carlos Alberto Gomes Cardim, Theodoro Rodrigues de Moraes e Miguel Carneiro Junior. Anuário do Ensino do Estado de São Paulo, 1907-1908, p. 384.
} 
primeira que começou a despontar em torno dos anos de 1880, interessada na organização do ensino secundário e superior, preocupada em produzir material didático aos colégios de formação das elites brasileiras.

A expansão do ensino público primário, como um acontecimento inaugurador, bem como a demanda de livros escolares daí procedente, mobilizou toda uma geração que se debruçou sobre essa produção. Além disso, a valorização das experiências pedagógicas desses sujeitos passou a ser fortemente considerada por parte dos editores como critério de escolha dos autores. O critério de seleção voltava-se para os que acompanhavam os avanços pedagógicos dos países nos quais a alfabetização se estendia para a grande maioria da população. Assim, a qualidade principal exigida do autor de livro didático para a escola elementar, era sua capacidade de bom escritor, ou seja, possuir as qualidades literárias para atingir a especificidade de um público infantil e juvenil. No entanto, a seleção das obras para a instrução pública paulista contava, em boa medida, com as relações que esses sujeitos estabeleciam com as instâncias do poder.

O professor Thomaz Galhardo, como era conhecido, soube equacionar todos os pré-requisitos para estar entre os principais autores de séries graduadas de leitura: era formado pela Escola Normal de São Paulo, angariava larga experiência como docente na instrução pública elementar, era um sujeito engajado nas associações e agremiações de professores, foi membro do Conselho de Instrução Pública - órgão responsável pela seleção de livros didáticos para o sistema educacional paulista - além de exercer cargos no alto escalão da diretoria de instrução do estado de São Paulo ${ }^{5}$.

\section{A série graduada de leitura: Na escola e no lar}

\section{Cartilha da Infância}

Cartilha da Infância inaugura a série graduada de alfabetização e leitura, Na escola e no lar, destinada para uso dos alunos do primeiro ano do ensino primário. Ao que tudo indica, sua primeira edição foi em 1888, já a segunda edição em 1891, ambas pela Teixeira \& Irmão - Editores. A partir de 1894, a Editora Francisco Alves comprou os direitos de publicação e editou a Cartilha até 1992, totalizando 233 edições ${ }^{6}$.

Na pesquisa realizada em diversos acervos, obtivemos informações de vinte e uma edições da Cartilha da Infância, entre 1888 e 1992, das quais tivemos acesso à vinte exemplares. As edições consultadas revelam muitos aspectos da produção e circulação desta obra. Primeiro, evidencia a permanência de uma prática escolar por pelo menos cento e quatro anos, apesar das mudanças ocorridas nos métodos de alfabetização e leitura.

\footnotetext{
${ }^{5}$ Sobre a trajetória de Thomaz Galhardo, consultar Alcanfor (2016), com a tese intitulada " Professor Thomaz Galhardo: produção, circulação e práticas de alfabetização e leitura -séculos XIX e XX”.

${ }^{6}$ Como não foram localizados os primeiros números da Cartilha da Infância, tínhamos informações imprecisas quanto à data de sua primeira edição. Considerando os anúncios e matérias publicados sobre a Cartilha, a partir de 1888, no jornal A Província de São Paulo, optamos por manter esta data como marco da primeira edição. Os anúncios são publicados a partir de janeiro do referido ano, portanto, o livro provavelmente havia sido impresso em 1887. Quanto à data da segunda edição, 1891, extraímos a informação da pesquisa realizada por Marcia Razzini (2007) sobre a produção de livros didáticos em São Paulo, especificamente aqueles publicados pela Teixeira \& Irmão - Editores. O exemplar mais antigo da Cartilha da Infância, ao qual tivemos acesso, foi uma microfilmagem da $41^{\mathrm{a}}$ edição de 1908 , pertencente ao Acervo da Fundação Biblioteca Nacional -Brasil.
} 
Segundo, a média de edições publicadas por ano é um importante indício da circulação e uso deste livro por várias décadas, mantendo-se praticamente inalterável em sua materialidade ${ }^{7}$.

Outra evidência, é quanto ao papel dos editores no processo de produção da Cartilha. No período em que foi editada pela Teixeira \& Irmão - Editores (1888-1893), a Cartilha provavelmente teve duas edições, mesmo sendo aprovada pelo Conselho Superior de Instrução Pública de São Paulo e adotada, na sequência, para o ensino público, no início do ano de 1888 (A PROVÍNCIA DE SÃO PAULO, INSTRUÇÃO PÚBLICA, 14/02/1888).

Com a instalação de uma filial da livraria Francisco Alves em São Paulo, no ano de 1894, o número de edições aumentou consideravelmente. No mesmo ano, a editora comprou os direitos de publicação da Cartilha da Infância, lançando inicialmente uma nova edição de 20.000 exemplares ${ }^{8}$.

Essa tiragem justifica-se pelo fato de o editor ter conquistado um potencial comprador, a Diretoria de Instrução Pública de São Paulo, sonho de todas as casas editoriais do período. No entanto, as relações entre editora e Estado não se efetivaram apenas pela influência política de Francisco Alves, lembrando que, neste período, Thomaz Galhardo exercia o cargo de oficial maior na Diretoria de Instrução e era membro do Conselho Superior de Instrução Pública, órgão responsável pela seleção dos livros escolares para as escolas do Estado de São Paulo. Por conseguinte, a relação que Thomaz Galhardo estabeleceu com o núcleo do poder foi determinante para que, tanto a Cartilha da Infância, como os demais livros da série que viriam posteriormente, circulassem nas escolas públicas com o "selo" de aprovação dos órgãos competentes de fiscalização da literatura escolar.

A partir da segunda edição (1891), a Cartilha da Infância sofreu modificações e foi ampliada pelo professor recém-formado pela Escola Normal de São Paulo, Romão Puiggari. Não sabemos quais mudanças Puiggari fez na obra, até porque não localizamos a primeira edição para cotejarmos as alterações. A alegação de que o afastamento de Thomaz Galhardo do magistério inviabilizou o aprimoramento da Cartilha da Infância reconhecendo a importância da participação de Romão Puiggari em sua reformulação parece mais um pretexto para lançar o jovem professor no circuito de autores de livros didáticos.

Seu nome permaneceu na Cartilha até as edições de 1950. Após a Cartilha da Infância, Puiggari não realizou nenhum outro projeto editorial com Thomaz Galhardo. Até mesmo porque suas opções metodológicas ganhariam rumos diferentes das de Galhardo. Sua diferenciação foi marcada pelos projetos independentes e pelas parcerias com o professor Arnaldo de Oliveira Barreto.

No prefácio, Ao leitor, Thomaz Galhardo justifica a opção pelo método silábico. Segundo ele, "os modernos sistemas de ensino de leitura, conquanto baseados sobre o método silábico, ora muito prolixos ora muito resumidos, não produzem o resultado a que

\footnotetext{
${ }^{7}$ De 1888 a 1893 a Cartilha da Infância teve de 2 a 3 edições; de 1894 a 1908 foram 37 edições; de 1908 a 1924, 68 edições; de 1924 a 1939, 31 edições; de 1939 a 1947, 22 edições; de 1947 a 1953, 16 edições; de 1953 a 1957, 11 edições; de 1957 a 1961, 16 edições; de 1961 a 1964, 07 edições; de 1964 a 1969, 10 edições; de 1969 a 1979, 06 edições; de 1979 a 1992, 07 edições.

${ }^{8}$ Contrato firmado a 03 de abril de 1894. Livro de contrato da Editora Francisco Alves. Arquivo do LIHED/UFF.
} 
se propõem que é: ensinar a ler bem, no menor espaço possível de tempo" (GALHARDO, 1911, p. 07).

Reconhecendo esses inconvenientes e defendendo o método da silabação como o mais apropriado para a conjuntura educacional brasileira, o autor enfatiza que, dos três métodos de ensino da leitura (antigo ou da soletração, moderno ou da silabação, e moderníssimo ou da palavração), optou-se na Cartilha pelo meio termo, em cuja base foi escrito o presente sistema.

Convém assinalar, que o método empregado na Cartilha da Infância buscava a rapidez na aquisição do código alfabético, o que fazia a excelência de um método para o público em geral. Isto porque, não podemos esquecer que existia outro mercado, frequentemente subestimado, da educação doméstica.

Esse cruzamento entre o mercado escolar e o mercado doméstico tende a desaparecer, ao longo do século XIX, com a escolarização em massa, a organização dos programas de ensino, a divisão em séries, entre outras. No entanto, como bem lembra Choppin (2009), essa estratificação não se efetuou de maneira uniforme, uma vez que esse entrelaçamento variou de acordo com a demanda de ensino.

Além disso, os editores e os autores, por sua vez, tinham interesse por razões essencialmente econômicas em apagar a distinção entre ensino doméstico e ensino escolar, o que fez com que um grande número de livros fosse conhecido por esses dois públicos consumidores, já que os "editores frequentemente assinalam a natureza dual de seu leitor na primeira capa ou na página do título" (CHOPPIN, 2009, p. 28).

Notemos quanto a esse último aspecto, que o próprio título da série de livros de leitura de Thomaz Galhardo, Na escola e no lar, sugere essa dualidade. Neste mercado da educação doméstica, adotam-se os livros produzidos aos primeiros anos do ensino e a mãe de família é frequentemente considerada digna de assumir a responsabilidade dessas aprendizagens, ainda que sem competência técnica particular (HÉBRARD, 1995; CHARTIER, 2005).

É também a este mercado legítimo e atuante que Thomaz Galhardo, em sua Cartilha, dedica o prólogo Duas palavras às mães de família. Lembrando que, no prefácio, não há uma definição específica a quem se destina a aplicação do método da Cartilha. Apesar disso, ao dirigir-se às genitoras, Galhardo esclarece sobre os propósitos de se alfabetizar uma criança, evidenciando o papel da escola e, principalmente, do professor nessa tarefa cheia de obstáculos que se revela o ensino da leitura. Para ele, esses obstáculos têm diversas causas, "algumas das quais são relativas à péssima organização das escolas; outras, à deficiência da maior parte dos sistemas de leitura existentes; outras, aos vícios adquiridos pelas crianças no primeiro ensino que lhes é ministrado no lar" (GALHARDO, 1911, p. 07).

Com base nas edições que consultamos da Cartilha da Infância, de 1908 a 1992, verificamos que pouco se alterou em sua materialidade. Até 1930, a obra tinha sessenta e três páginas, nas quais eram distribuídas as trinta e três lições e oito histórias para o exercício de leitura. A partir desse período, com as mudanças ortográficas, uma página foi suprimida, assim como a última lição, do $p h$ e do $y$. Também foi atualizada a história "Estrada de Ferro", devido às alterações ocorridas nas ferrovias brasileiras.

Exceto a primeira lição, das vogais, em nenhuma edição as demais lições acompanham ilustrações. A imagem de crianças brincando com as letras aparece na parte superior do texto, passando por apenas três modificações em sua trajetória editorial. 
Chartier (1990, p. 132-133) chama a atenção para essas "identificações explícitas, que designam e classificam os textos, criando em relação a eles expectativas de leitura, antecipações de compreensão". São formas apresentadas na "imagem, no frontispício ou na página do título, na orla do texto ou na sua última página”, como marcas que sugerem uma leitura e constroem um significado.

$\mathrm{Na}$ trajetória editorial da Cartilha, apenas três atualizações ocorreram nas imagens das histórias, ganhando tons mais infantis a partir da década de 1960. Essas correspondências entre imagem e texto funcionam como "protocolos de leitura ou lugares de memória do texto", caracterizadas como uma leitura que exige sinais visíveis de identificação, portanto, "mais facilmente decifráveis por parte dos leitores inábeis" (CHARTIER, 1990, p. 130).

A Cartilha da Infância surpreende por suas particularidades formais - tipográficas - quase estáticas, por tantas décadas. A partir da relação entre texto, livro e compreensão emerge outro aspecto que condiz com a história das práticas de leitura. Trata-se dos usos dos textos, que dizem respeito às marcas textuais: "estável na sua letra e fixo na sua forma", tornando-o objeto de leituras contrastantes, já que um livro muda "enquanto muda o seu modo de leitura" (CHARTIER, 1990, p. 131).

\section{Segundo Livro de Leitura para a Infância}

O Segundo livro de leitura para a infância foi lançado sete anos após a Cartilha. Sua primeira edição foi em 1895, pela Editora Alves \& Cia., sendo editado provavelmente até a década de $1960^{9}$.

Destinado para o segundo ano escolar, o Segundo livro se propõe a dar continuidade ao processo de aprendizagem da leitura iniciado com a Cartilha. Sua distribuição já estava garantida para o provimento das escolas públicas paulistas com a aprovação pelo Conselho Superior de Instrução Pública, em $1894^{10}$.

Das modificações apresentadas verificamos que, pelo exemplar mais antigo que conseguimos consultar, de 1908, havia cento e vinte e quatro páginas, nas quais foram distribuídas quarenta histórias para o exercício da leitura, todas acompanhadas de ilustrações em preto e branco. Nas demais edições que consultamos, $79^{a}$ edição - 1956, e $81^{\text {a }}$ edição-1960, a obra passou a ter cento e cinco páginas e trinta e quatro histórias. As modificações mais significativas dizem respeito à organização e distribuição das histórias, as quais são completamente alteradas, além das modificações textuais empregadas. Em suma, alguns textos são reformulados, outros suprimidos, e vários títulos são modificados.

$\mathrm{Na}$ apresentação da obra, dirigida Ao leitor, Galhardo afirma que essa forma de organização dos textos, desenvolvidos de forma gradual, justifica-se deliberadamente "para prender a irrequieta atenção dos alunos e habituá-los a ligar ideias", que "devem ser lidas pelo professor às classes superiores da escola, para serem por estas reproduzidas, primeiro verbalmente e depois por escrito, na própria linguagem dos alunos" (GALHARDO, 1908).

\footnotetext{
${ }^{9}$ Localizamos quatro edições do Segundo livro: $15^{\mathrm{a}}$ ed. - 1908, no Acervo da Fundação Biblioteca Nacional; a $73^{\text {a }}$ ed. - 1952, no Acervo do LIHED; a 79ª ed. - 1956, no Centro de Referência em Educação Mario Covas; e a 81 a ed. - 1960, no Acervo Histórico do Livro Escolar da Biblioteca Monteiro Lobato. Para fins de consulta usaremos como referência a edição de 1908.

${ }^{10}$ A respeito dos livros aprovados pelo Conselho, consultar Razzini (2007).
} 
A disposição dos textos, empregada no Segundo livro, é criada em função dos leitores que desejam ou pensam atingir. A exemplo da fórmula dos editores de Troyes, analisados por Chartier (1990), essa intervenção editorial tem por objetivo remodelar a apresentação do texto, multiplicando os capítulos - mesmo que essa divisão não resulte de qualquer necessidade narrativa ou lógica -, aumentando o número de parágrafos, dividindo o texto em unidades menores. Segundo o autor, "há nesta divisão, que fraciona o texto com títulos de capítulos ou parágrafos uma leitura que não é de forma alguma virtuosa nem contínua, mas que pega no livro e o larga, que só decifra facilmente sequências breves e independentes, que exige identificações explícitas" (CHARTIER, 1990, p. 175).

Em sua materialidade, o Segundo livro também foi modificado quanto ao aspecto gráfico das capas e ilustrações, as quais permaneceram como forma de estabelecer a relação entre imagem e texto, ou lugares de memória.

No catálogo da Livraria Francisco Alves, a obra é divulgada como um trabalho "ornado de numerosas ilustrações", feitas por Thomaz Galhardo ${ }^{11}$. As imagens a que se referem também foram atualizadas nas edições cotejadas. Resta-nos dúvidas se realmente as ilustrações da primeira edição, que provavelmente correspondem à $15^{\text {a }}$ edição, de 1908 , foram feitas pelo autor.

O destaque que os editores dão à iconografia da obra evidencia, sobretudo, a recorrência à imagem como uma prática usual no período de sua produção. No discurso dos intelectuais, as imagens tinham fundamental importância na formação do espírito infantil, principalmente na fase inicial da alfabetização e da leitura.

Por meio de uma análise pormenorizada das imagens do Segundo livro, em dois momentos da história de suas edições, verificamos que elas representam as concepções de aprendizagem do período, como forma de o aluno ter contato com situações mais concretas de aprendizagem. Entretanto, é preciso atentar para as condições em que o processo de construção da obra didática ocorreu, uma vez que as ilustrações serviram como um instrumento a mais na veiculação da cultura europeia. Esses elementos são perceptíveis nos cenários, nas vestimentas, nos gestos e posturas civilizadas, nos animais europeus, como um padrão a ser incorporado pelas crianças brasileiras (BITTENCOURT, 2008).

Além do que, as obras de Thomaz Galhardo eram impressas na Europa, como a maioria das obras dos autores brasileiros. A preferência pelas tipografias francesas se deve, sobretudo, pelo barateamento e pela qualidade do produto europeu, colocando em desvantagem a produção dos impressores brasileiros que pagavam mais impostos pelo papel do que pelos livros importados (HALLEWELL, 1985).

Se o fator pecuniário se tornou preponderante no encaminhamento das publicações para fora do Brasil, especificamente para a França, um outro elemento precisa ser destacado nessa relação comercial, para além da produção de livros didáticos, que tem a ver com a opção de setores das camadas dominantes pela França. Essa relação deve ser vista na trama de interesses econômicos e culturais estabelecida entre os dois países, e não simplesmente como decorrência de "importação de ideias". Havia um interesse mútuo pela implementação de uma "cultura francesa" no Brasil e o livro didático tornou-se uma mercadoria moderna e necessária para o processo "civilizatório" (BITTENCOURT, 1993, p. 89-91).

\footnotetext{
${ }^{11}$ Relação completa das obras publicadas pela Livraria Francisco Alves, 1954. Acervo LIHED.
} 


\section{Terceiro Livro de Leitura para a Infância}

O Terceiro livro de leitura para a infância, em continuidade à série graduada, $\mathrm{Na}$ escola e no lar, teve sua primeira edição em $1902^{12}$, sendo editado pela Alves \& Cia., em 1906, dois anos após o falecimento do autor. Antes mesmo de sua primeira edição, o Terceiro livro já havia sido aprovado pelo ato governamental de cinco de setembro de 1901, para adoção nas escolas públicas do Estado de São Paulo.

Thomaz Galhardo contava com a publicação do seu Terceiro livro pela Editora Francisco Alves, como ocorreu com a Cartilha e o Segundo livro. Não atingindo o intento, e para atender ao pedido da Diretoria de Instrução Pública de São Paulo, o autor mandou imprimir o livro na Europa, pela Typographia Aillaud \& Cia. Além de custear as despesas de impressão, Galhardo se responsabilizou por sua divulgação e comercialização, colocando-o à venda em sua residência "à rua Barão de Iguape, $n^{\circ}$ 64" (O ESTADO DE S. PAULO, ANÚNCIOS, 29/01/1904).

Devido ao alto custo de impressão, supomos, com base no exemplar $n^{\circ} 6957$, rubricado por Thomaz Galhardo, que o autor tenha mandado imprimir uma tiragem de 10.000 exemplares, contando que as tiragens dos livros didáticos, na época, variavam em torno de 5.000 mil exemplares, conforme afirma Hallewell (1985). A editora Francisco Alves normalmente imprimia de 5.000 a 10.000 exemplares de cada obra.

Analisando as edições podemos constatar que, mesmo após compor o catálogo da Francisco Alves, as alterações materiais são praticamente irrisórias. A primeira edição contém quarenta e seis lições, as quais estão distribuídas em cento e oitenta e seis páginas. A $11^{\mathrm{a}}$ edição passa a ter cento e noventa e duas páginas, sendo acrescida a partitura do Hino Escolar, cuja letra de autoria de Thomaz Galhardo faz parte da XL lição (GALHARDO, 1911).

$\mathrm{Na} 30^{\mathrm{a}}$ edição, manteve-se o mesmo número de páginas com quarenta e nove lições. Não se trata de novas histórias, mas do desmembramento das lições, Uma heroína e Últimas cenas, em duas partes (GALHARDO, 1944).

Também foram mantidas, nas sucessivas edições, a indicação na folha de rosto da aprovação e a adoção da obra pelo Governo do Estado, as dedicatórias, o prefácio Ao Leitor, o mesmo número de páginas e os mesmos títulos das histórias, todos na mesma ordem, diferentemente do Segundo, no qual a sequência das histórias foi completamente alterada. Esse formato se explica levando em conta a importância que o autor dá para a multiplicação das recapitulações e dos resumos que permitem voltar a ligar o fio de uma leitura interrompida.

A obra provavelmente circulou até 1960 e apenas dois aspectos materiais diferenciam as edições: a alteração na capa, presente na edição de 1944, idêntica à capa do Segundo livro, e a atualização de algumas ilustrações que acompanham as histórias, mas permanecendo os mesmos títulos.

\section{CONSIDERAÇÕES FINAIS}

\footnotetext{
${ }^{12}$ Localizamos quatro edições do Terceiro livro: $1^{\mathrm{a}}$ ed. - 1902 e $11^{\mathrm{a}}$ ed. -1911 , no Acervo da Fundação Biblioteca Nacional - Brasil; 19ª ed.-1919, na Biblioteca do Livro Didático - FEUSP; e dois exemplares da $30^{a}$ ed. - 1944, no Centro de Referência em Educação Mário Covas e no Acervo do LIHED.
} 
Neste trabalho apresentamos os resultados da análise das obras de Thomaz Galhardo, destacando a produção e circulação dos livros escolares deste professor, que compunham a série graduada de leitura $\mathrm{Na}$ escola e no lar. Com essa série Galhardo inaugura, como seus contemporâneos, a literatura escolar brasileira.

Sua popularidade deve-se, entre outras questões, à experiência como professor de instrução pública para as séries iniciais, e às funções que exerceu, com poder de influência, sobre o Conselho de Instrução Pública - órgão responsável pela seleção dos livros de leitura - e nos cargos que ocupou na Diretoria de Instrução de São Paulo.

A influência de Thomaz Galhardo na Diretoria de Instrução favoreceu, sobremaneira, a aprovação e adoção dos seus títulos, bem como foi o vetor para que suas obras estivessem entre as mais vendidas pela editora Francisco Alves.

Este estudo possibilitou-nos compreender a complexidade e especificidade do livro didático, tendo como princípio norteador o cuidado em estabelecer sua distinção quanto aos demais impressos. Situando a produção didática de Thomaz Galhardo em uma dimensão mais ampla, para além dos estudos limitados ao conteúdo das obras, compreendemos que o livro escolar é um objeto, cuja fabricação evolui de acordo com o progresso das técnicas de fabricação do livro, das mudanças do mundo da edição, dos contextos políticos e econômicos. Destacamos, também, a série graduada de leitura, $\mathrm{Na}$ escola e no lar, como suporte privilegiado do conteúdo educativo, além de um importante instrumento pedagógico para a formação de várias gerações.

\section{REFERÊNCIAS}

ALCANFOR, Lucilene Rezende. Professor Thomaz Galhardo: produção, circulação e práticas de alfabetização e leitura - séculos XIX e XX. Tese (Doutorado em Educação), Educação: História, Política, Sociedade. Pontifícia Universidade Católica de São Paulo (PUC-SP): São Paulo, 2016.

BITTENCOURT, Circe Maria Fernandes. Livro didático e conhecimento histórico: uma história do saber escolar. Tese (Doutorado em História), Faculdade de Filosofia, Letras e Ciências Humanas. Universidade de São Paulo, São Paulo, 1993.

Autores e editores de compêndios e livros de leitura (1810-1910). Educação e Pesquisa, São Paulo, v. 30, n. 3, set./dez. 2004.

Livro didático e saber escolar (1810-1910). Belo Horizonte: Autêntica Editora, 2008 .

CABRINI, Conceição. Memória do livro didático, os livros de leitura de Felisberto de Carvalho. Dissertação de Mestrado em Ciências da Comunicação (Escola de Comunicações e Artes-ECA). Universidade de São Paulo: São Paulo, 1994.

CHARTIER, Anne-Marie; HÉBRARD, Jean. Discursos sobre a leitura (1880-1980). São Paulo: Ática, 1995. 
CHARTIER, Anne-Marie. Dos abecedários aos métodos de leitura: gênese do manual moderno antes das leis Ferry. 2005, mimeo.

CHARTIER, Roger. A história cultural: entre práticas e representações. Rio de Janeiro: Bertrand, 1990.

CHOPPIN, A. L'histoire des manuels scolaires: une approche globale. Histoire de l'Éducation, Paris, n. 9, p 1-25, 1980.

O manual escolar: uma falsa evidência histórica. História da Educação, Pelotas, v. 13, n. 27, p. 9-75, jan./abr. 2009.

ESCOLANO, Augustín. Em la España de entresiglos. Cultura - Revista de história e teoria das ideias, Lisboa, v. 13, II série, 2000/2001.

GALHARDO, Thomaz. Terceiro livro de leitura para a infância. Paris-Lisboa: Typografhia Aillaud \& Cia, 1902.

. Segundo livro de leitura para a infância. Rio de Janeiro, S. Paulo, Belo Horizonte: Francisco Alves \& Cia, 15. ed., 1908.

Cartilha da infância - ensino da leitura. Rio de Janeiro, S. Paulo, Belo Horizonte, Paris, Lisboa: Francisco Alves \& Cia, Aillaud, 58. ed., 1911.

Terceiro livro de leitura para a infância. Rio de Janeiro, S. Paulo, Belo Horizonte: Livraria Francisco Alves, 30. ed., 1944.

HALLEWELL, Laurence. O livro no Brasil. São Paulo: T. A. Queiroz, EDUSP, 1985.

MONARCHA, Carlos. Escola Norma da Praça: o lado noturno das luzes. Campinas: Editora da Unicamp, 1999.

2012.

. O livro didático como mercadoria. Pro-Posições, v. 23, n. 3, p. 51-66, set./dez.

ORIANI, Angélica Pall. Série "Leitura Infantis" (1908-1919), de Francisco Vianna, e a história do ensino da leitura no Brasil. Dissertação (Mestrado em Educação) - Faculdade de Filosofia e Ciências, Universidade Estadual Paulista. Marília, 2010.

PANIZOLLO, Claudia. João köpke e a escola republicana: criador de leituras, escritor da modernidade. Tese (Doutorado em História da Educação) - Programa de Estudos PósGraduados em Educação: História, Política, Sociedade, Pontifícia Universidade Católica de São Paulo (PUC-SP). São Paulo, 2006.

RAZZINI, Marcia de Paula Gregorio. Produção de livros didáticos e expansão da escola elementar em São Paulo: a Tipografia Siqueira e a Editora Melhoramentos (1889-1940).

Relatório de conclusão de estágio de pós-doutorado (Educação: História, Política, Sociedade). Pontifícia Universidade Católica de São Paulo (PUC-SP), 2007. 
VALDEZ, Diane. A representação de infância nas propostas pedagógicas do Dr. Abilio Cesar Borges: o barão de Macahubas (1856-1891). Doutorado (Faculdade de Educação Universidade Estadual de Campinas). Campinas, 2006.

Recebido: $18 / 03 / 2017$

Aprovado: 20/04/2017 